International Journal of Learning Management Systems

@ 2014 NSP

Natural Sciences Publishing Cor.

http://dx.doi.org/10.12785/ijlms/020201

\title{
Analysis of Images in Logatie, a Reading Book for First Year Female Students in Saudi Arabia
}

\author{
Lina Saeed Bashatah \\ Manchester University, UK \\ *Email: ayman.nassoura@psc.edu.sa
}

Received: 3 Oct. 2012; Revised: 2 Nov. 2012; Accepted: 7 Dec. 2012

\begin{abstract}
The aim of this study is to analyse the presentation of images about Saudi culture in children's curriculum books. It shows the image types in the first year reading book and how they represent and illustrate family members' roles within the Saudi family. The researcher focused on one theme in a reading book-My Familybecause of its importance and her personal interest. Semiotics analysis, which is considering qualitative data analysis, was selected as the appropriate method to answer the research questions posed. The researcher decided to use the qualitative method rather than quantitative, which is often used for this kind of study to analyse the data more in depth as Greener (2011) mentioned. For this study the findings have shown that the images from the family theme illustrate the Saudi stereotypes of all the family members- women as housewives and men in educated or economic roles.
\end{abstract}

Keywords: Images, Logatie book, Semiotics, Saudi Culture, Role of Family Members Theme.

Introduction

The idea for this article emerged from the researcher's personal and professional research participation in various studies, including one on the curriculum for preschool education in Oman and one on the reality of the preschool programme in Saudi Arabia.

The researcher employed a qualitative approach to analyse the images in a first year reading book for female students in Saudi Arabia. While separate versions of the book are intended for girls and boys, the versions are indeed the same. In addition, the researcher considered Nice's warning (cited in Bashatah ,2011) that adults must cautiously render opinions on children's books, because children have special requirements, characteristics and cognitive processes and adults sometimes do not understand children's needs and wants.

Many studies have been conducted about book analysis in Saudi Arabia but the majority have taken the quantitative approach. Taiemah (2004) mentioned a number of studies such as Al-Semairi's (1998) about analysing the reading and writing book for first year girls in Saudi Arabia and evaluated it from the education experience standard and Bradah's (1974) study about analysing common children's stories in Egypt. What is more, Al-Fiefie (2012) analysed the third year English language curriculum of secondary schools in Saudi Arabia. However, the researcher decided to use the qualitative approach not only from her own calling but also for subjective reasons and as an important need, not a scientific luxury (Taiemah, 2004). On the same level, she has chosen to analyse images because it is considered as a valuable type of study. Although researchers have often set aims, they may achieve other purposes; in this kind of study the researcher needs to be reflective and not a reader of meaning (Cohen, Manion \& 
Morrison, 2011). In this respect, the researcher has used the semiotics approach to analyse the images Hunter (2012) used the semiotic method for his study about the visual analysis of Hunan Province online destination images and mentioned that semiotics can connect the signs with the material symbolism and that it helps the researcher to follow the culture changes over time, also it describes the image to show the real result of experience. What is more, Goodnow (2010) has used this approach to analyse photographs of Obama and Clinton and has mentioned Kress and van Leeuwen's 1996 book about The Grammar of Visual Design that the semiotic method is 'an appropriate model through which to dissect the Time photographs because of its examination of both content and style' (p. 407). Thus the semiotic method is the best method to use for this study.

In this respect, the researcher decided to do this kind of study not only for image analysis, but also to present recommendations for the authorities to modify the children's curriculum and make it match their needs, culture and development. Also, to alert the stakeholders to pay more attention to the curriculum and work to improve it to be appropriate with the children's culture. Thus, the researcher's aim is to analyse the representations portrayed by the images shown within the My Family theme reading book and also to discuss the presentation of the roles of the family members within the reading curriculum.

\section{Research Questions}

The aim of this research is to explore the meaning of the images in a reading book for first year female students in Saudi Arabia and to investigate the family roles presented in the family theme of the curriculum.

1. What do the images in the first year reading book represent?

2. How do the images of the My Family theme reflect members' roles within the family?

Questions focusing on children were selected because analysis of children's images in Saudi Arabia is lacking and the audience for these images is children. The family theme was chosen, because the researcher wanted to explore the stereotyping of family members present in this curriculum.

\section{Data Analysis}

In the social sciences, interest in visual research is increasing, and different methods can be used to reach findings (Jenkings, Woodward \& Winter, 2008). However, the researcher chose to employ a semiotics approach, because it can be used to explore the meaning of the images from signs (Prosser, 2006). According to Punch (2011), Swiss linguist Saussure and American philosopher Pierce founded the semiotics approach. Saussure pointed out that signs can be codes and Pierce stated that anything that can be seen, is a symbol (Punch, 2011). Pierce described the semiotician's role as 'identify[ing] mechanisms by which meaning is produced (the most common ones are metaphor, metonymy and opposition) and devis[ing] techniques using these mechanisms for interpreting qualitative data' (as cited in Punch, 2011, $\mathrm{p}$. 199). This approach enables the educational researcher to more clearly note the details of the images and more objectively analyse the text and design of the images (Goodnow, 2010). Although Cohen, Manion and Morrison (2011) claimed that influences such as background and culture prevent researchers from objectively analysing images, the semiotics approach 'has been proven to be a powerful tool for further analysing how such references function' (Codognet, 2002, p. 48). This criticism did prompt this researcher to adopt Walcott's (1994) system, which breaks down analysing images into three steps: description, analysis and interpretation (as cited in Qualitative Data Analysis, 2013).

\section{Description}

The Arabic title of the book is Logatie, when translated into English means My Language. This book was initially authored and later revised by an educational expert group within the Saudi Education Ministry, most recently in 2009 but is republished annually. The copy used in this research was published in 2012-13. The book is divided in two parts, one for the first semester and one for the second, both with 
colourful covers. The cover for the first term has Arabic letters and the logo of the Education Ministry in the top right corner. In the middle of the cover page, the title, grade level (the first year of elementary school) and a statement that this version is for girls are written in a large font. Although it seems logical that the girls and the boys' versions must be different, a comparison found that they are exactly the same. The labels might be required because many schools separate girls and boys in the first year.

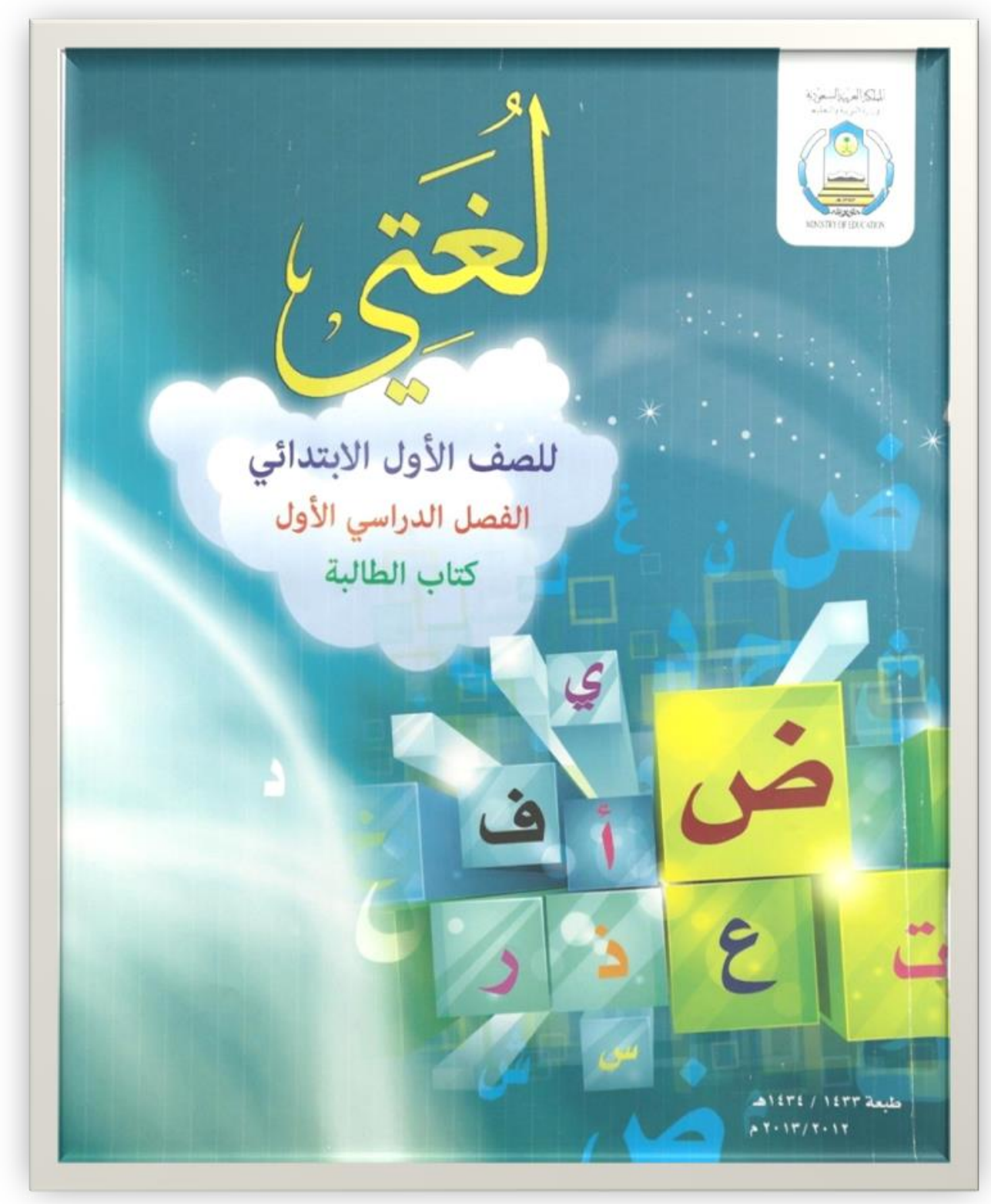

Figure 1. Front Cover

The first page presents some points to help parents use the book with their children. Next comes the table of contents, which emphasises the importance of parents' roles in teaching their children. The book has eight themes for the year, three for the first semester-My Family, My School, and My City- 
followed in the next semester by-My Health and Safety, My Toys and Hobbies, My Food and Diet, Animals, and Occasions. On the first page of the section for each theme, a table shows the skills that children should learn during that particular theme.

\section{Analysis and Interpretation}

Following Cohen, Manion and Morrison's (2011) argument that the steps of analysis and interpretation are related, the researcher merged these steps. In this article, the researcher describes the My Family theme images in general and then presents an in-depth analysis of certain images selected to answer questions suggested by Rose (as cited by Cohen, Manion \& Morrison, 2011). My Family is the first theme of the first semester, indicating its importance. In addition, this theme is easy for children to understand, reflects the reality of their life and addresses concepts appropriate for their age and knowledge base. Other evidence pointing to the importance of the theme of My Family includes the image of a family on the cover of the second semester book, even though the content does not focus on families.

Gradation is utilised in the presentation of concepts. The skills for the theme are organized from easiest to hardest. For example, the first skill is listening, and at this stage, the child only listens for letter sounds and then identifies where the letters are in the word-at the beginning, middle or end. In general, the images for the My Family theme are clear, colourful and appropriately bright. They are equal to the size of a young adult's palm, not too big or too small for children. This size indicates that the images were designed purposefully for their audience of children. Many images are repeated in the My Family theme section accompanied by written instructions for the children to 'see and describe what you see'. What is being shown is then described.

Despite an inclusion system in some Saudi schools, the book has no images of disabled people, most noticeable in the My Family theme. This absence of representation could influence children's acceptance of people with disabilities. Similarly, there are no images of nannies, maids or drivers, even though the majority of middle-class Saudi families employ at least one such household assistant. This discrepancy shows a lack of awareness and fails to educate children about the stratification and emphasis on class in their society. Moreover, the images show neither poor nor rich people but only one social class, although all societies have different social classes.

Likewise, all the people represented have white skin, but the majority of people in Saudi society have dark skin, and a minority are black. Al-Bakr (2005) noted this absence of diversity in the first year reading book. She also observed that, while the Kingdom of Saudi Arabia is a large country with different regions whose holy places draw people with Asian and African roots, these people are not represented in the book.

In another departure from reality, there is only one picture of a computer and none of laptops, iPods, iPads or any entertainment technology, although the book was published as recently as 2012 when such devices were widespread in society. 


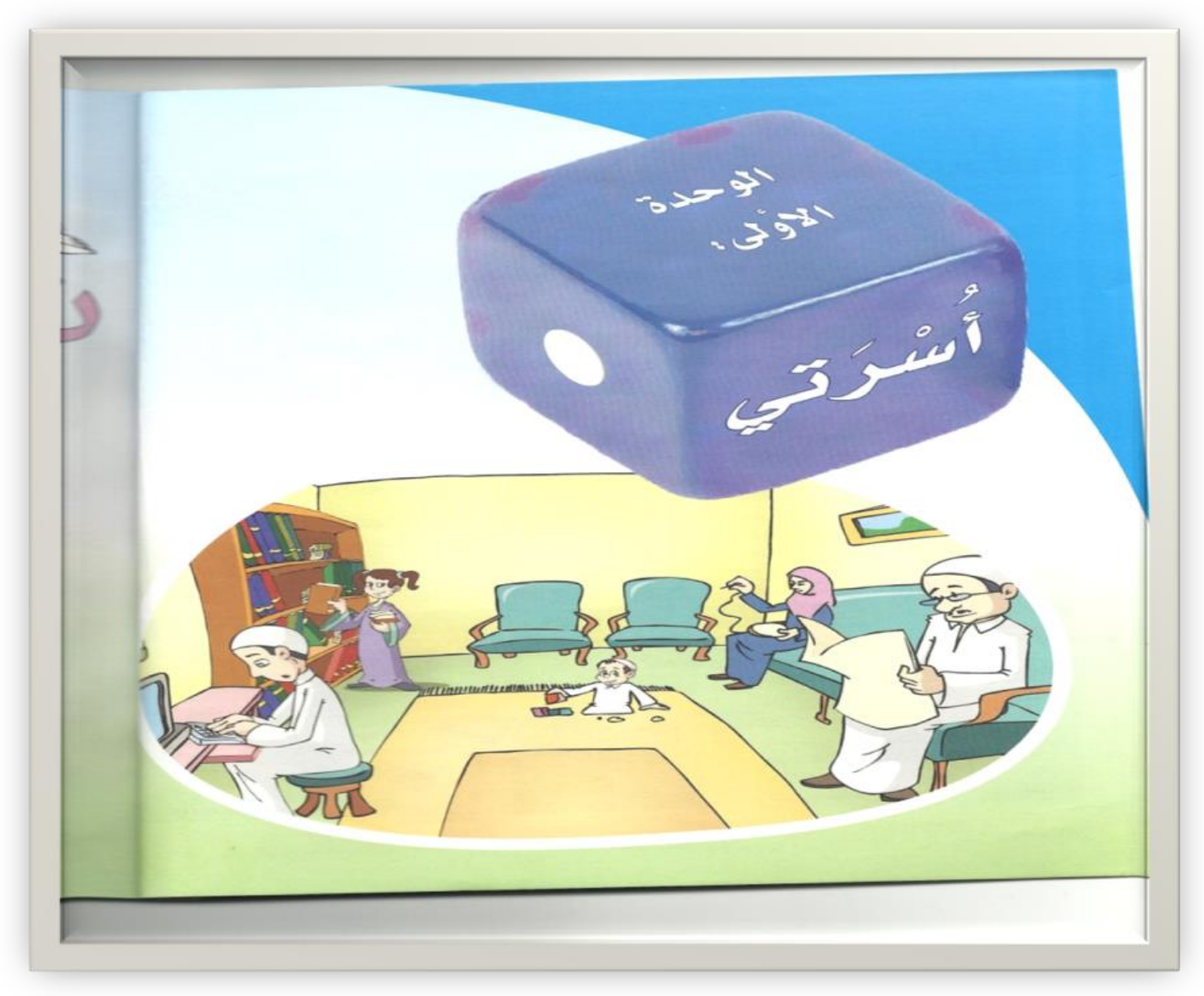

Figure 2. First Image of the My Family Theme

Figure 2 introduces the My Family theme, therefore it is the primary image analysed. The other images analysed support the findings concerning this first image. Figure 2 depicts the present day, not an earlier era. The image is clear, colourful and appropriately sized. The page is well organized. At the top of the page, inside a die, is written in a large font the number and name of the theme-The First Theme: My Family. This design presents two concepts-a number and a word-in a way that is attractive to children, colourful and instructional. However, some children might not recognize the image of a die, because this generation plays mostly with technology, however the shape and the colour of the die is likely to appeal to children.

\section{The Place and the Furniture}

Analysis of this image can be separated into analysis of the place and furniture and of people. The image shows the living room where the entire family is present. The room is wide and large enough for all the people in it, indicating that the family is middle-class. The image is colourful with the walls being yellow and on the right wall a square painting in a brown wood frame. The subject of the painting is not clear, perhaps a landscape because its primary colours are green and blue. There is a large, green sofa big enough for four people and also two wooden chairs of the same colour. The green floor has a yellow and gold carpet, reflecting the Saudi preference for carpeting over wood floors in their hot climate. A wooden desk with a small chair holds a computer, but there is no television. This suggests that possession of a computer is more important than that of a television, since the image shows a computer but not a television, even though most Saudi families have not only a television but a satellite receiver to watch 
many channels from around the world. At the back left of the room, a wooden storage unit with four shelves displays books of different sizes and colours. This inclusion attests to the value of reading and the importance of books. The parents sit opposite to their children, perhaps to supervise and control them. The mother and the husband sit slightly apart and, while they are in the same room, they are engaged in their own interests.

\section{The People: The Family Members}

The image shows family members of different ages, an adult mother and father, a brother and sister who are young adults and one child playing on the ground. However, as an introduction to the family, this image should also include grandparents because in Saudi culture, many extended families live together in one home. Figure 3 shows the grandfather-identified by his old age, beard, cane and stooped back-as a visitor to the family.

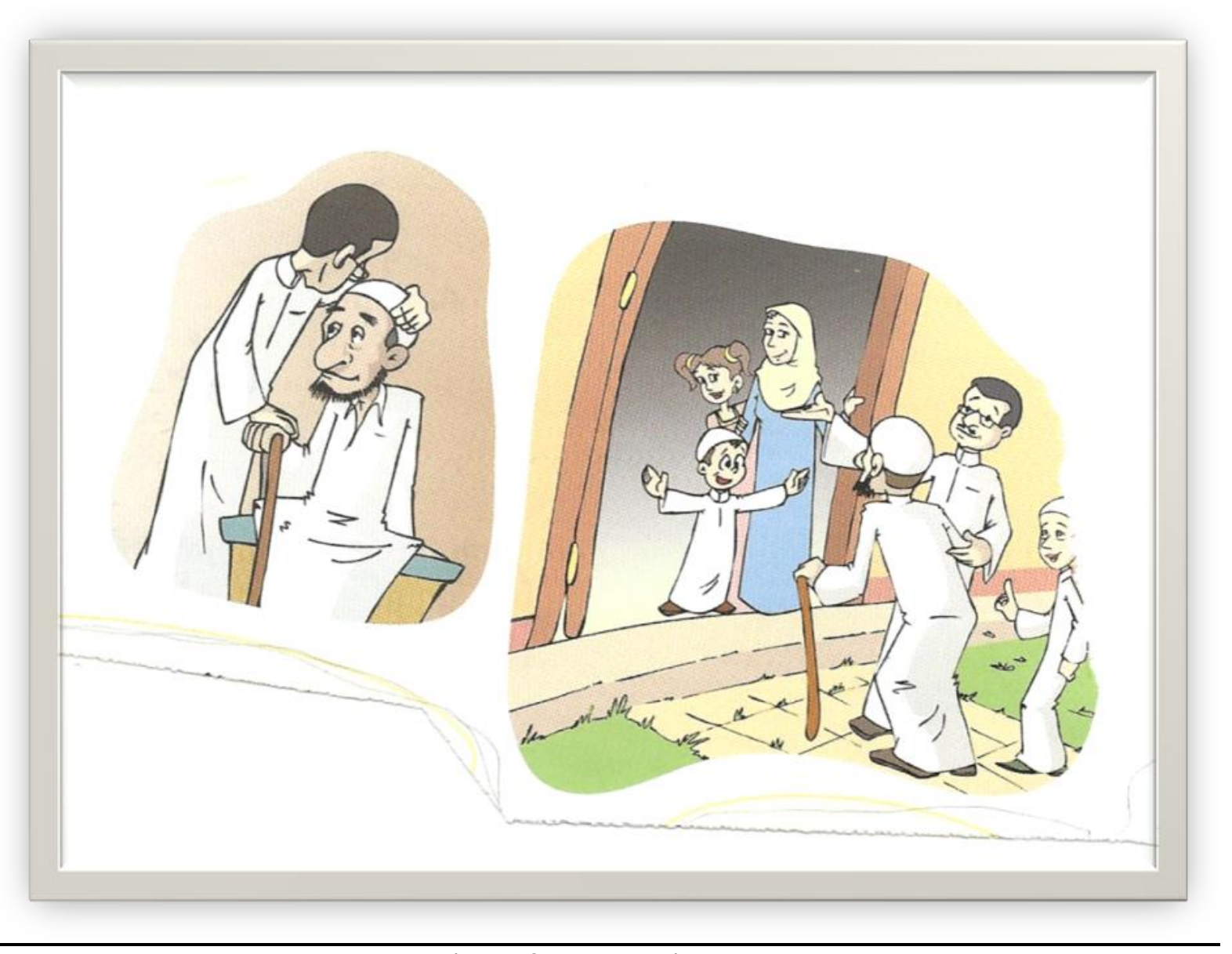

Figure 3. The Family Members

The family members stand in the doorway to happily welcome the grandfather. This situation illustrates the change in the structure of the Saudi family from extended to nuclear. In this image the father kisses the grandfather's head and lets him sit in the chair-a religious and cultural gesture of respect. Islam teaches respect for the elderly, and in Saudi and Arabic culture, younger people kiss old people on their heads or hands. The image does raise the question of where the grandmother is.

Returning to Figure 2 (the first image of the My Family theme), the depiction of two boys and one girl reflects the old Arabic cultural preference for boys. For example, some believe that boys will carry on the family name and help their parents in their old age and that raising girls is more difficult. 
Unfortunately, these beliefs persist among some families and are validated by the inclusion of this image in the curriculum, even though these beliefs violate Islam's respect for women and granting of the same rights to women and men.

Typically, family members have a variety of facial features and colours, and children resemble different parents. All the family members in this image have the same skin colour but different eye colour, size and shape. The girl and young boy have brown eyes, while the older brother has green eyes. The parents' small eyes cannot be seen clearly, but the children's eyes are large. The older brother and sister have square eyes, while the young boy's are circular. The mother, older boy and girl all have long noses that end in a triangle, while the young boy and father have big noses that end in a circle.

All the family members wear clothes that could be worn outside the home. The father and boys are dressed in cotton hats and thoubs, which are the formal, traditional clothes for men in Gulf and some Arabic countries. It does not seem logical that the father and boys would wear these clothes all the time, because they are not comfortable and are considered formal in Saudi Arabia. At home, the brothers could wear pyjamas or sport suits, for example, and the father a jlabya, which is similar to the thoub but has short sleeves and is made of cotton and is looser.

The mother and daughter also wear outdoor clothes inside the home. The mother wears a scarf in the house which does not reflect reality. For religious reasons, Saudi women wear a scarf to cover their hair from the view of strangers or male non-relatives but go without at home, where all the men are relatives. The mother and girl wear long dresses with long sleeves as they would to go outside the home, although there are house clothes for the women appropriate for their age and Saudi culture. The female clothing in this image reflects Saudi culture, not Islam as some believe. Islam encourages women to wear a veil outside but not inside the home where women can wear whatever they want in front of relatives. However, Saudi culture supports this visualisation of women having to cover themselves at all times. In another discrepancy regarding their attire, all the family members wear shoes. This might happen in the winter, but a variety of slippers can be worn at home and during the frequent hot weather in Saudi Arabia.

All the family members in the image are busy doing something and are not facing the viewer, except for the girl and young boy who smile. The characters' activities reflect their roles. The father wears glasses and reads a newspaper, showing that he is educated. The older boy sits at the office unit and works on the computer, indicating that he is working or studying. In contrast, the mother and girl are shown in domestic roles with the mother sewing and the girl arranging books on the shelves. The young boy sits on the floor, smiling and playing with coloured cubes, and seems happy with this simple toy.

The rest of the images in the My Family theme also depict the mother in domestic roles-smiling as she waters her garden flowers in Figure $\mathbf{4}$ below

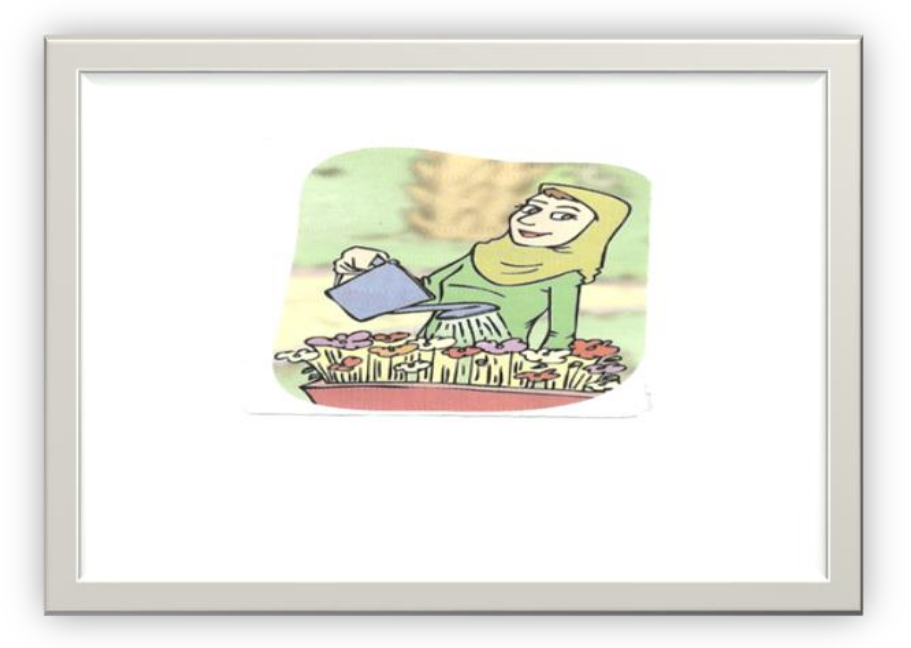

Figure 4. Domestic Role-Watering Flowers 
and her facial features expressing dissatisfaction, as she sweeps the floor in Figure 5 below



Figure 5. Domestic Role-Sweeping Floor

and looking sarcastic, as she makes coffee in the kitchen in Figure 6 below

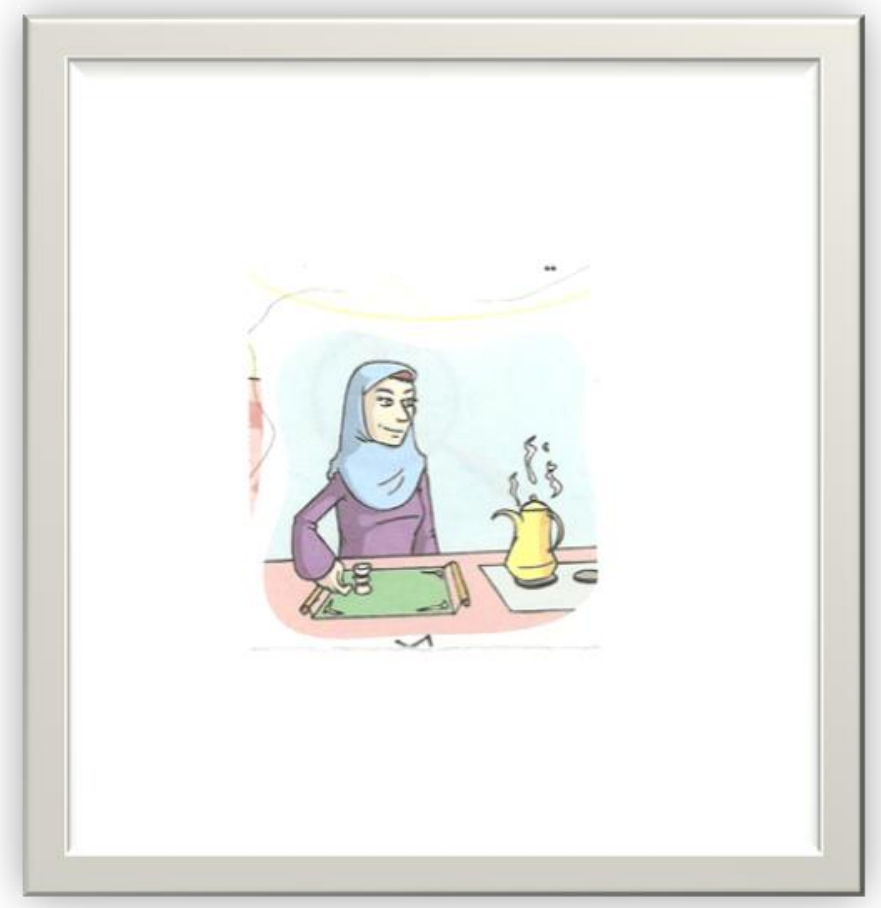

Figure 6. Domestic Role-Making Coffee 
It is not clear from her emotions in the three images whether she likes what she is doing, interestingly the young daughter is presented helping her mother in domestic roles, for example as in Figure 7 below. The daughter has a happy expression as she cleans the sofa and window, the father is not shown helping the women at home in any way.

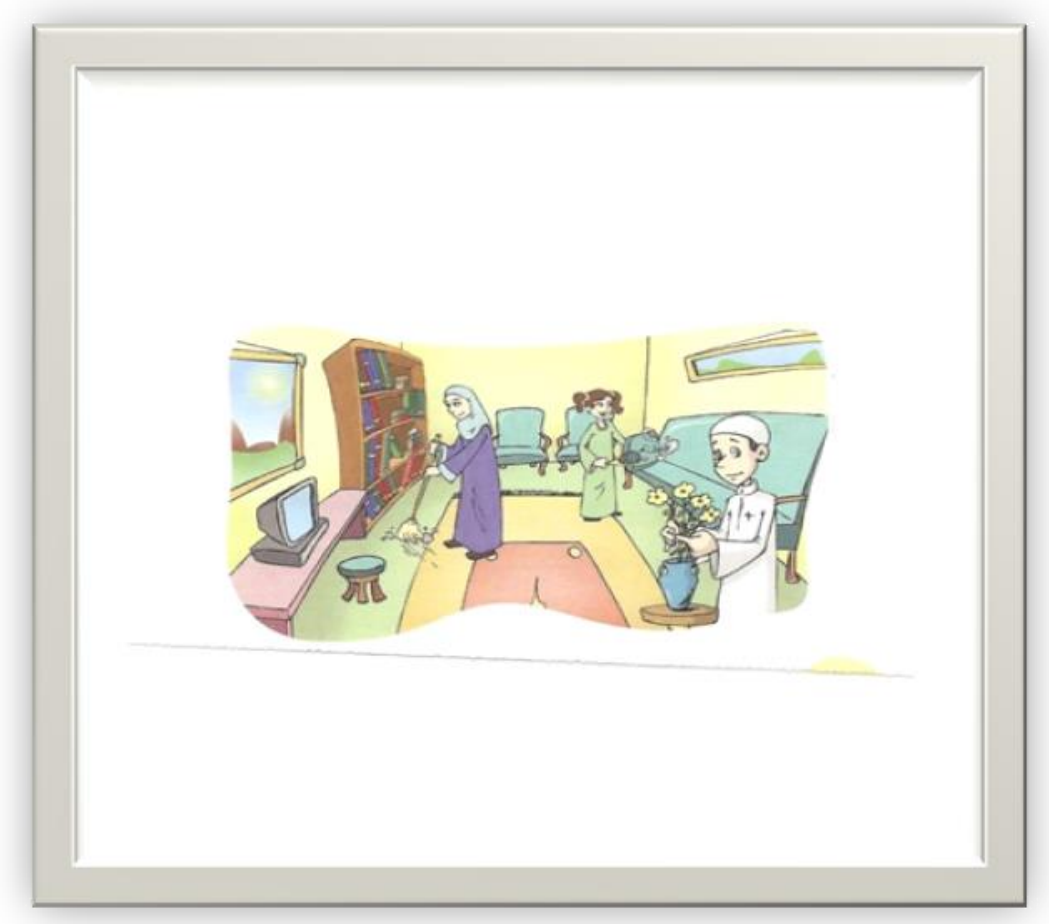

Figure 7. Daughter in Domestic Role

However, in Figure 8 below the boy arranges the flowers, looking puzzled, perhaps because this chore is not his usual role or he thinks it shames him to help his mother.



Figure 8. Son in Domestic Role 




Figure 9. Children in Domestic Roles

Additionally, in Figure 9 above, the boy cleans a window like the girl is doing, however the girl cleans alone, but another hand helps the boy. The hand appears to be the mother's, indicating that she is not confident in the boy's cleaning abilities and has to supervise him or perhaps that she sympathizes with him because this task is not his typical role. The mother might see cleaning as the girl's role and so lets her do it alone, although the boy is older than the girl as indicated in Figure 2 previously. The images show only one occupational role for women as teachers, as shown in Figure $\mathbf{1 0}$ below. 


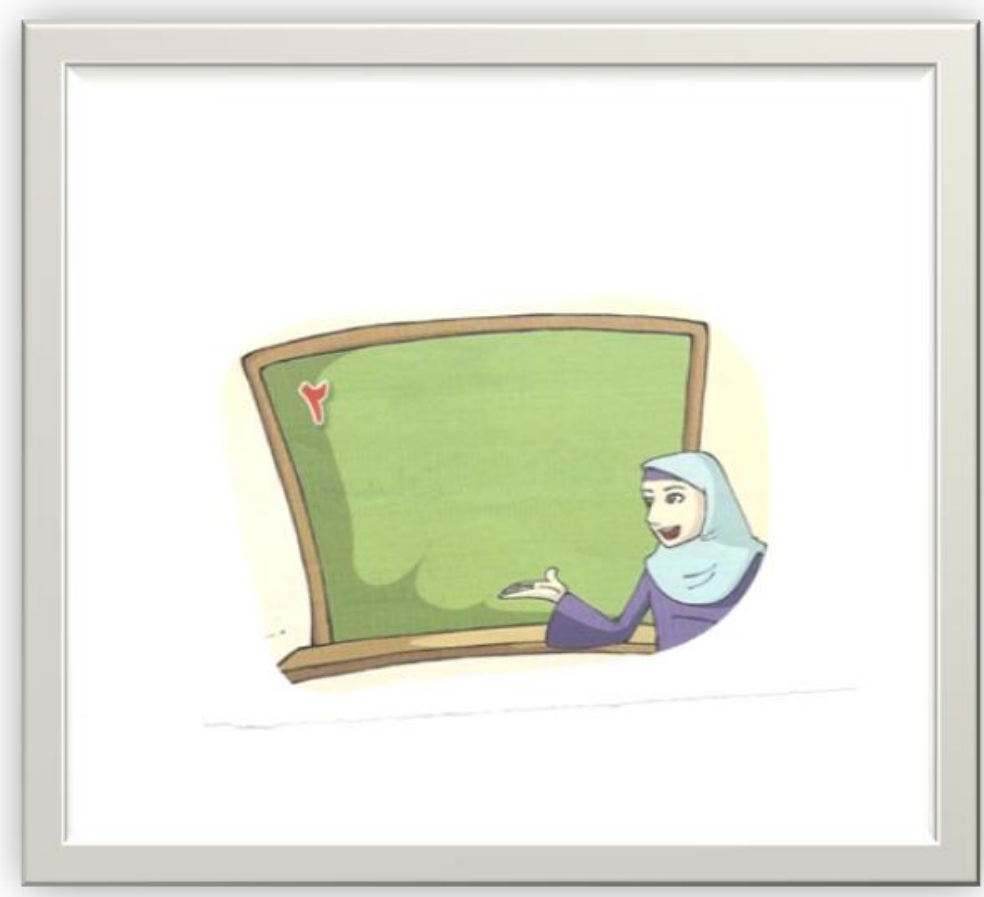

Figure 10. Woman in Occupational Role

In reality, Saudi women can work in many different jobs and receive salaries equal to men, especially in government positions such as lecturers at public universities. Other images, in contrast, depict men in different jobs-as teachers, engineers and train drivers-as indicated in the following Figure 11. 

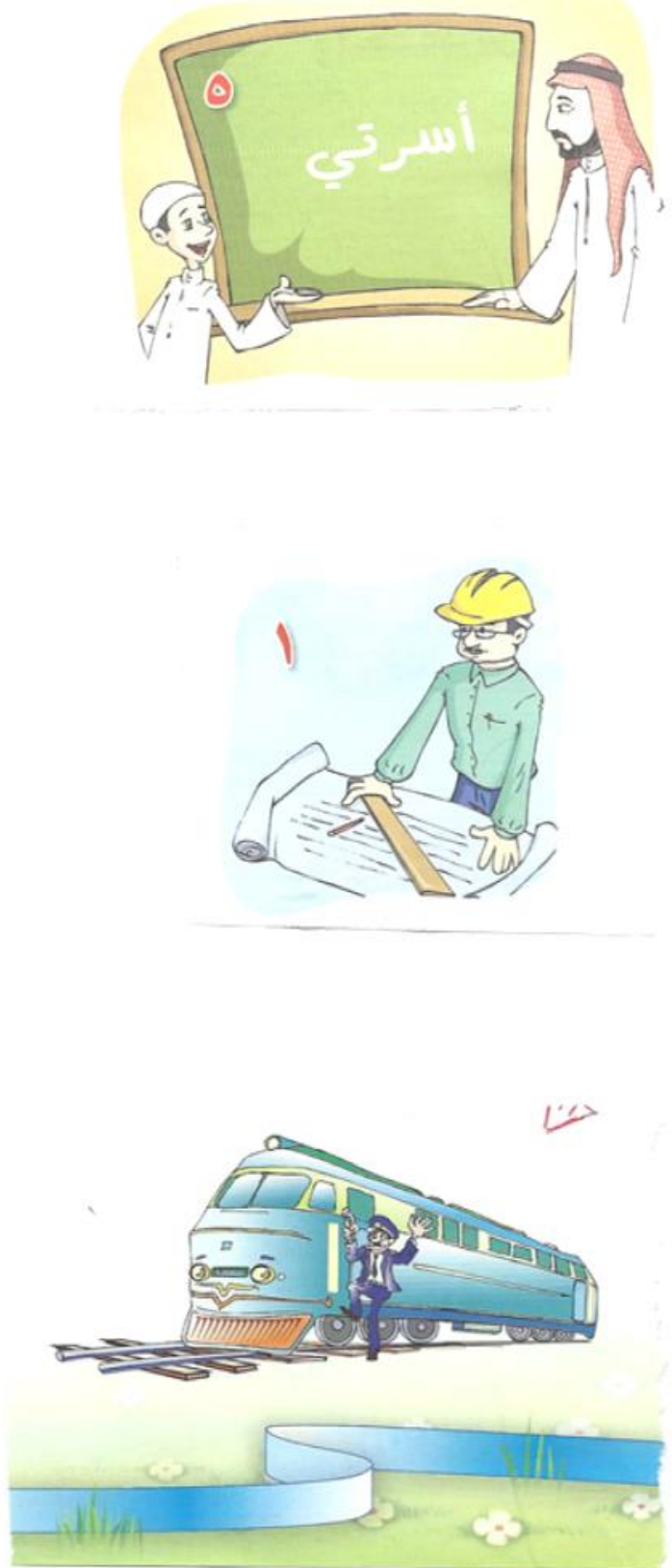

Figure 11. Men in Occupational Roles 
Moreover, boys and men perform a variety of sports and activities, such as playing ball and swimming, even the young boy is shown playing ball and riding a bicycle in Figure 12 below.

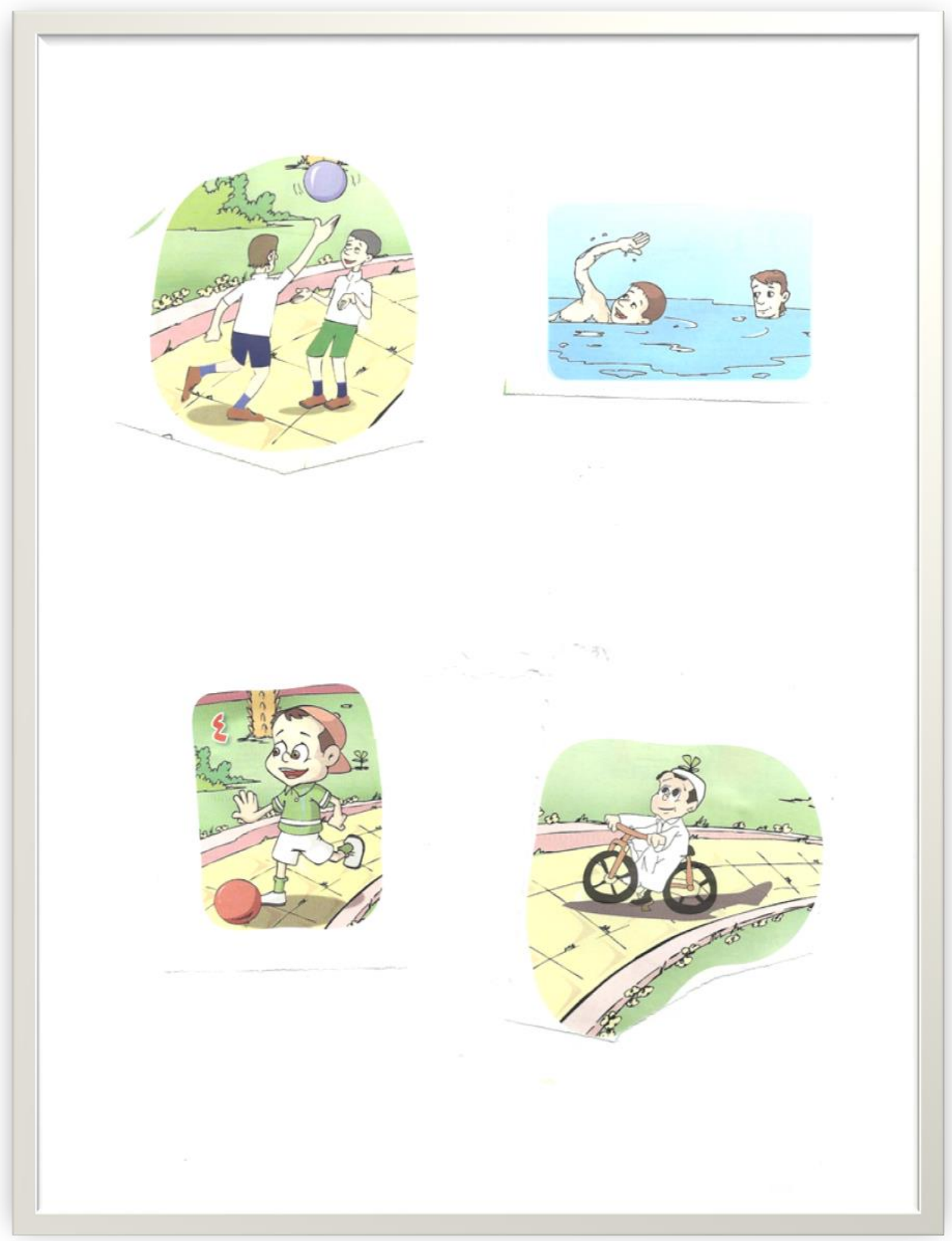

Figure 12. Boys and Men in Recreational Sports Activities 
However, there are no images of the mother or daughter engaged in any kind of sport or activity requiring mobility, instead the girl holds a doll, draws and colours in as depicted in Figure13 below.



Figure13. Girls in Recreational Activities

These images do not reflect attitudes towards physical activity among the many Saudi women and girls who go to the gym and play sports. Perhaps the authors do not show females in sport clothes, because some families believe that trousers should be worn only by boys and men.

\section{Conclusion}

This study supports the implications of its analysis with the findings of other research projects. The images in this book are considered as subliminal messages that reach children without direct instruction (Cohen, Manion \& Morrison., 2011). Al-Bakr (2005) called these kinds of messages the 'hidden curriculum', defined as any concept which intentionally or unintentionally conveys specific knowledge to students without them being aware of it. These family themed images in the first year curriculum may convey subliminal messages about, for example, children with disability, race, technology and the social roles of men and women.

The absence of children with disabilities, who are present in society in large numbers, could be considered marginalisation of this group. According to the World Health Organisation, the Arab world has approximately 40 million people with disabilities, of whom more than $90 \%$ are children or adolescents (as cited by the Arab Council of Childhood and Development, 2012). In regard to race and class, the images depict no human variety showing all the characters having the same skin colour, and there are no images of any black people, drivers, maids or other domestic assistants, all of whom are part of Saudi society. Brunette et al. (as cited by Bashatah, 2011) stated that such depictions of race could shape the environment around the child. Thus, these images in the curriculum could build such concepts in children's minds, powerfully affecting how they perceive their environment. In addition, the absence of technology is illogical in an era of widespread global technology, even Al-Bakr criticised the absence of 
technology in her book published in 2005. This lack in the first year reading book does not match with the $21^{\text {st }}$ Century reality in which children live.

The most remarkable aspect of the family themed images is their depiction of male and female social roles. The mother is presented as a housewife with a limited occupation as a teacher, but in reality women are significant among the 50,000 Saudi students who have obtained scholarships and are studying in different fields abroad. Moreover, women's participation in the workforce has increased, rising from $5.4 \%$ in 1992 and to $12 \%$ in 2009 (Achievements of the Plan, 2011). Finally, there are no images of women engaged in any kind of sport or physical activity, even though two Saudi women participated in the 2012 London Olympics, one in judo and one in the 800 metres competition (Al-Ashieree, 2012).

To sum up, the semiotic analysis carried out in this article on the My Family theme images from the first year girls reading book revealed that the expert group which created this book took care with the design but not the content of the images. All the images are clear, colourful and appropriately sized for the audience of children, but the messages that the images could be sending did not receive appropriate attention. The images from the My Family theme present Saudi stereotypes of all the family memberswomen as housewives and men in educated or economic roles. Also, that boys have access to and can undertake more and different activities- such as sports-while girls have a limited range of activities even though they are in the same age group.

\section{References}

Achievements of the development plan.(2111). Retrieved from http://www.mep.gov.sa/index.jsp;jsessionid=211BA9E4284F285DC3691B9475958D46.alfa?event=Artic leView\&Article.ObjectID $=81$

Al-Ashieree, A. (2012).The Saudi women's names who posts in the London Olympics .Dow newspaper. Retrieved from http://www.daoo.org/dim/news.php?action=show\&id=46267

Al-Bakr, F. (2005). Fund my school is closed. House Majority: Riyadh.

Al-Fiefie, Z. (2012). Educational values contained in English language course of the year school secondary in Saudi Arabia. Unpublished thesis (MA), Umm Al-Qura University.

Arab Council of Childhood and Development. (2012). The rights for the disable children in 2012. Retrieved from http://www.arabccd.org/page/866

Bashatah, L. (2011). Children's images in the media. Assignment: University of Sheffield.

Codognet, P. (2002). Ancient images and new technologies: The semiotics of the Web. Leonardo, 35(1), 41-49.

Cohen, L., Manion, L., and Morrison, K. (2011). Research methods in education (7th ed). New York: Routledge.

Goodnow, T. (2010). Visual bias in Time's 'the great divide': A semiotic analysis of Clinton and Obama photographs. American Behavioral Scientist, 54(4), 406-416.

Greener, I. (2011). Designing Social Research A Guide for the Bewildered. London: SAGE.

Hunter, W. (2012). China's Chairman Mao: A visual analysis of Hunan Province online destination Image. Tourism Management 34, 101-111 
Jenkings, K., Woodward, R. and Winter, T. (2008). The emergent production of analysis in photo elicitation: Pictures of military identity. FORUM: Qualitative Social Research, 9(3). Retrieved from http://www.qualitative-research.net/fqs/

Nina-Pazarzi, E and Tsangaris,M (2008). Constructing Women's Image in TV Commercials : The Greek Case. Indian Journal of Gender Studies, 15(1), 29-50.

Posser, J. (2006, July). Researching with visual images: Some guidance notes and a glossary for beginners. Real life methods: A node of the National Centre for Research Methods at the Universities of Manchester and Leeds. Retrieved from: http://www.socialsciences.manchester.ac.uk/morgancentre/realities/wps/3-2006-07-rlm-prosser.pdf

Punch, K. (2011). Introduction to research methods in education. London: Sage. Qualitative data analysis. (2013). Manchester: The University of Manchester.

Saudi Education Ministry. (2009). Logatie (2012-13 ed). Al-Riyadh: Saudi Education Ministry.

Taiemah, R. (2004). The Content Analysis in Humanities. Cairo:Dar Al-fkr Al-Arabie. 